\title{
Da curadoria de artista a alguma outra coisa
}

Lucas Bambozzi é artista e curador independente, com trabalhos já exibidos em mais de 40 países. Desde os anos 90 explora novas possibilidades de arte envolvendo meios de comunicação tendo sido um dos iniciadores do Festival arte mov e dos projetos Labmovel, Multitude, ALTav, Prenúncios + Catástrofes, dentre outros. É professor no curso de Artes Visuais na FAAP e finaliza seu doutorado na FAUUSP em 2019, com pesquisa envolvendo campos informacionais em espaço públicos.

<bambozzi@gmail.com>

ORCID: 0000-0002-0288-9048
Resumo $\mathrm{O}$ texto especula a permeabilidade entre práticas artísticas e curatoriais, a partir de uma série de projetos que poderiam ser entendidos como propostas ambivalentes, cruzando o terreno entre essas atividades. Se um artista pode ser um curador, que escolhas essa condição ambígua determina? A serviço de que decisões e situações, para além da própria carreira, pode-se operar essa prática? Trata-se de um relato em primeira pessoa que se lança sobre as perspectivas reais de entendimento de possíveis tipologias da curadoria associada ao campo das artes e mídias. 0 texto aborda pensamos de críticos como Claire Bishop, Elena Filipovic, Hal Foster, Hans Ulrich Obrist e outros, em pensamentos que buscaram expandir o campo de atuação de artistas em relação a práticas curatoriais. Considerando um grande número de artistas atuantes nas confluências desse campo no Brasil, como os brasileiros Graziela Kunsch, Giselle Beiguelman, Fernando Velazquez, Marcus Bastos, Roberto Traplev, Kika Nicolela, Bruno Mendonça, Sonia Guggisberger, Claudio Bueno, Gabriel Menotti ou Daniel Lima, o texto enseja um novo ambiente para essas práticas, que envolvem novas configurações de espaços do tipo artist-run spaces (espaços autogeridos) ou exposições preparadas exclusivamente por artistas. Sem afirmar dogmas, arriscar genealogias ou pre-definir terrenos de atuação, o texto resvala pensamentos associados à frase "Não sabendo que era impossível, foi lá e fez", como o devaneio de um curador que acabou sendo sem saber que era ou podia ser.

Palavras chave Curadoria em novos meios, Artista etcétera, Artista-curador, Espaços autogeridos. 


\section{Of artist curationship to something else}

Abstract The text speculates on the permeability between artistic and curatorial practices, based on a series of projects that could be understood as ambivalent proposals, crossing the fields between these activities. If an artist can be a curator, what this ambiguous condition establishes? At which decisions and situations, beyond one's own career, this practice might operate and serve? This is a first-person report that inquires on actual perspectives of understanding possible types of curationship, including the media arts field. The text approaches thoughts of art critics such as Claire Bishop, Elena Filipovic, Hal Foster, Hans Ulrich Obrist and others, in considerations that sought to expand the field of artists acting in curatorial practices. Considering a large number of artists acting around this field confluences in Brazil, such as the Brazilians Graziela Kunsch, Giselle Beiguelman, Fernando Velázquez, Marcus Bastos, Roberto Traplev, Kika Nicolela, Bruno Mendonça, Sonia Guggisberger, Claudio Bueno, Gabriel Menotti or Daniel Lima, the article expects a new environment for these practices, which involves new models of artist-run spaces or exhibitions conceived exclusively by artists. By refusing dogmas, genealogies or pre-defining fields of actions, the text plays with the phrase "They did not know it was impossible, so they did it" like the reverie of a curator who ended up being so, unaware that he could be or was already being.

Keywords : New-media curation, The artist as a curator, Artist-run spaces, The artist-etc. 


\section{Da curadoria de artista a alguma outra coisa}

Este texto especula sobre a permeabilidade entre práticas artísticas e curatoriais, a partir de uma série de projetos que poderiam ser entendidos como propostas ambivalentes, cruzando campos possíveis entre essas atividades. Ao atribuir minha própria experiência, me vejo em uma narrativa na primeira pessoa, não exatamente por reproduzir uma síndrome identitária (típica daqueles que passam dos 50 , diriam alguns), mas porque percebo que essa narrativa pode produzir algum sentido em meio à vasta e recente literatura em torno do curationism (curacionismo?) e da ambiguidade existente nas múltiplas funções que envolvem o fazer artístico.

Passei o final dos anos 80 e o início dos 90 fazendo imagens em movimento. Às vezes isso era considerado vídeo, às vezes videoarte, às vezes arte, às vezes um cinema experimental, às vezes nada disso. Quando não era a realização de uma obra per se, muitas vezes resultava em proporcionar situações que permitissem que outros o fizessem, ou que pudessem tornar a cena (de artistas trabalhando com videoarte, no caso) um tanto mais visível.

Era em certa medida uma forma de tornar evidente que aquelas atividades não eram uma prática de um pequeno nicho, que eram válidas, que eram parte de um sistema de relações que poderia ser também pensado em um circuito maior, no circuito da arte, por exemplo.

\section{De como se enxergar artista}

Não frequentei escolas de arte. Fui aprendendo intuitivamente o que poderia ser arte quando o que fazia não era cinema, não era televisão, não era comunicação. E assim, sem querer, sem de fato ter maior clareza do 'jogo' da arte, fui me aproximando do que parecia ser uma arte sem lugar certo, uma arte incômoda, uma arte estranha ao seu próprio meio. E sem querer, também, fui me vendo como o que mais tarde me parecia ser "um artista que questiona a natureza e a função de seu papel como artista, um artista-produtor, um artista-teórico, um artista-professor, um artista-curador, um artista-etcétera", nas palavras do artista Ricardo Basbaum, que defende essa função múltipla do artista como sendo também, é claro, artística. Pois sem o pretender, eu me via comprometido com uma cena, em fortes ligações com os circuitos locais, e entendia essa prática justamente “como um desenvolvimento e extensão do 'artista-multimídia' que emergiu em meados dos anos 1970, combinando o 'artista-intermídia' fluxus com o artista-conceitual" (Basbaum, 2013).

Artistas como Peter Weibel, Susan Hiller ou Rafael Lozano-Hemmer há tempos misturaram suas atividades de autoria e curadoria. Jerremy Deller alcançou reconhecimento internacional tendo feito a curadoria de várias de suas exposições, incluindo suas participações na Bienal de Veneza em 2013 e em 2015, e a exposição Iggy Pop Life Class, uma coleção de desenhos de sessões de nus de Iggy (mas não apenas) para o Brooklyn Museum. A lista 
é grande, e se estende a Rirkrit Tiravanija, Joseph Kosuth, Martha Roesler, Golan Levin, Walid Raad e Akram Zaatari e muitos outros. Lozano-Hemmer foi o criador do Prêmio Vida ${ }^{1}$, que já estimulou centenas de projetos ligados a arte e inteligência artifical ao redor do mundo. Raad e Zaatari produziram Mapping Sitting (2002), um projeto sobre a história da fotografia de retrato amador e profissional no mundo árabe. 0 criador da primeira edição da Documenta, em Kassel, uma exposição de revitalização do cenário artístico no período pós-guerra, foi Arnold Bode, então um conhecido pintor alemão.

Claire Bishop, em What Is a Curator? The rise (and fall?) of the auteur curator comenta o quanto os papéis do artista e do curador convergiram, gerando troca constante de funções em âmbito criativo. $O$ endosso dessa visão é comentado também por David Balzer em Curationism: How Curating Took Over the Art World and Everything Else, bem como pelo crítico de arte e filósofo alemão Boris Groys, além de pesquisadoras como Elena Filipovic (autora de When Exhibitions Become Form: On the History of the Artist as Curator), que conduz uma série de publicações (online e impressas) a partir do projeto The Artist as Curator. ${ }^{2}$

Apesar da reincidência do assunto, Elena Filipovic argumenta que a história do artista como curador ainda precisa ser devidamente escrita. "Surpreendentemente, não existem estudos abrangentes sobre exposições pensadas por artistas, nem tentativas mais sérias de teorizar a especificidade dessas exposições" (Filipovic, 2015). Os estudos de Filipovic mostram que as exposições organizadas por artistas têm ficado fora dos estudos da história da arte que tendem a favorecer um foco em obras ou objetos autônomos. Por outro lado, há visões que apontam a proximidade das instalações produzidas por artistas da ideia da exposição pensada autoralmente.

Marcel Duchamp lançou a ambiguidade da escolha ou da seleção como obra em vários de seus trabalhos. The Box in a Valise (1938-42), uma espécie de mini-exposição, portátil e auto-curada, é um de seus legados mais nítidos nesse sentido. $O$ caráter anárquico e político pensado por Hélio Oiticica para Apocalipopótese (Aterro do Flamengo, RJ, em 1968), misto de trabalho e exposição, não caberia em nenhum pensamento curatorial do período - muito menos comportaria algum direcionamento institucional. Artistas como Marcel Broodthaers, que fez (auto)curadorias de suas retrospectivas, Martha Wilson e Martha Roesler, pelo pensamento crítico à ideia de exposição ou por não caberem na lógica do mercado, produziram obras que desafiam curadores a entrar num emaranhado de questões tipicamente processuais, nitidamente da natureza criativa ou combativa associada ao artista. É como se pedissem para os curadores pensarem um pouco mais como artistas.

Há claro, casos de artistas que se lançam em curadorias formais, pontualmente, como o de Maurizio Catelan, que assinou a edição da $4^{a}$ Bienal de Berlim, em 2006 (junto com Massimiliano Gioni e Ali Subotnick). E há casos reincidentes, como as curadorias de Peter Greenaway, gestadas em muitos de seus filmes e que se resvalam para espaços institucionais e formais como a mostra Obedience (2015) no Jewish Museum em Berlim (assinada junto com Saskia Boddeke), por exemplo. Filmes como Windows 
(que registra pessoas que caíram da janela, Act of God (pessoas atingidas por raios), $M$ is for Man, Music, Mozart e A walk through $H$ (um passeio por coincidências associadas às letras $\mathrm{M} \mathrm{e} \mathrm{H}$, respectivamente), mostram um pouco da obsessão de Greenaway por uma certa museologia baseada em coleções, repetições, catalogações, com reincidências em ícones do barroco e do renascimento e especial fixação pela pintura flamenca.

Um de seus últimos projetos, The Tulse Luper Suitcases (de $2003 \mathrm{em}$ diante, pois segue em processo), pode ser tanto entendido como uma recorrência explícita a seus filmes anteriores (Luper aparece nos filmes $A$ walk through H, Vertical Features Remake, The Falls e The Draughtsman's Contract) e como uma referência à própria valise (suitcase) de Duchamp. Sendo Greenaway um típico estrategista, nunca vamos saber ao certo a distância entre o discurso artístico e a informação mais objetiva.

O fato é que, muitas vezes, pela forma como a obra é organizada e apresentada, ou pela produção de obras que reúnem qualidades curatoriais, cada vez mais vemos artistas percorrendo terrenos que seriam típicos da curadoria.

Assim, a lista das múltiplas funções e atividades associadas ao artista cresce exponencialmente nas últimas décadas.

\section{Novos etcéteras}

Entre nós, José Roberto Aguilar, Ricardo Basbaum, Graziela Kunsch, Giselle Beiguelman, Fernando Velazquez, Marcus Bastos, Roberto Traplev, Jorge Menna Barreto, Kika Nicolela, Bruno Mendonça, Sonia Guggisberger, Claudio Bueno, Gabriel Menotti, Fred Paulino, Daniel Lima ${ }^{3}$ ou este que vos escreve, todos tiveram seus momentos de curadores, por motivos muito diversos.

Dentre os motivos mais reincidentes dentre esses nomes, talvez esteja a necessidade de criar situações e condições para determinadas exposições acontecerem, e com isso evidenciar e colocar a público certas pesquisas. Interessam neste texto entender a diferenças entre os que viabilizam exposições para si próprios e os que promovem acesso a outros artistas, funcionando como agentes de uma distribuição de oportunidades. São ações coletivas, projetos temáticos, criação de dispositivos, organização de leilões, salões e exposições propriamente ditas, que envolvem intercâmbio de papeis, e nos quais recai sobre o artista a urgência de atuar como produtor ou agente cultural. Algumas comparações entre contextos fazem ressoar de alguma forma os postulados do texto $O$ autor como produtor, escrito em 1934, em que Walter Benjamin observa formas de produção artística (notadamente a escrita, mas não apenas) em que o autor passa a ser também o editor, o publisher de seus próprios trabalhos. Está embutida nessa premissa uma ideia combativa em que o artista atua menos pensando em proporcionar entretenimento ao público, mas age também como um instrumento de conscientização e possível transformação da realidade cultural e social. 
Muitas vezes esse é o (único) caminho para a viabilização da própria obra, bem como a perspectiva de criação de novos circuitos para que a obra exista ou circule, que exige do artista o desempenho do papel de produtor.

No Brasil, vemos a lógica do artista multitarefa (novamente o artista etc) girar por vezes em torno da precariedade associada ao sustento da profissão, exclusivamente artística. Sendo a cultura um campo de baixos salários e de pouco reconhecimento formal e a arte contemporânea um campo movediço, sem grandes certezas, as atividades conexas passam a ser exercidas por uma quantidade enorme de artistas que não conseguem sê-lo em $100 \%$ do seu tempo, e se alimentam das bordas desse circuito periférico.

Soma-se a esse cenário de desdobramento de papeis, o surgimento de mecanismos que valorizam não apenas o artista mas o curador, com recursos destinados tanto à elaboração de obras como para a realização de curadorias.

Uma série de fatores derivados do contexto de precarização do trabalho vem gerando efeitos colaterais que de fato exigem a profissionalização da função de produtor por parte do artista, em seus aspectos legais e fiscais, ou seja, oficializou-se o agenciamento de si, ao mesmo tempo em que minguam condições para a subsistência da própria atividade artística.

De uma forma ou de outra, os mecanismos existentes no circuito cultural demandam posturas que acabam por sobrepor atuações profissionais que antes tinham perfis distintos.

No meu caso, percebo que atuações como agenciamento, fomento, formação, ensino, seleção, escolha, escrita, crítica, direcionamento do olhar ou, de fato, 'curadoria', embutidas no perfil típico de um artista-etc, estavam em projetos e atividades que foram iniciadas simultaneamente, no início mesmo de minha prática artística, como o festival de arte eletrônica ForumBHZvideo (1991-1995), quando fazia sentido dizer que videoarte era algo importante em relação a vários outros meios, afirmando uma perspectiva independente que ajudou a tornar Belo Horizonte um pólo de produção de vídeo autoral; nas mostras Radical Vídeo e Videoautor do Museu da Imagem e do Som de São Paulo, onde fui coordenador do departamento de vídeo entre 1993 e 1995; nos projetos de exibição e distribuição de vídeo da Associação Diphusa ${ }^{4}$ (1996-1999).

o desenvolvimento desse tipo de projeto tipicamente híbrido, envolvendo conceitos, escolhas, programação cultural e, sim, 'pensamentos artísticos', se tornou uma prática constante no período em que trabalhei com José Roberto Aguilar na Casa das Rosas (1995-1999), quando fui o responsável por exposições como BitFoto (1995), Arte Suporte Computador (1997) e Imanência (1999). Foram estimulados projetos de muitos artistas que ali estrearam suas experiências ditas "multimídia". Seguiu-se na Casa uma lógica de desmitificação da autoridade curatorial, em dinâmicas onde um artista convidava o próximo, e em que a perda do controle era parte de um processo rico e permeado de experiências que com certeza marcou o percurso de muitos artistas. Esses projetos repercutiram para além dos circuitos originalmente ensejados, fazendo envolver outras práticas e curadores, convidando artistas a se desdobrarem em pensadores, performers - agentes 
etcéteras -, expandindo uma certa cena de arte e mídia que nunca se conformou em se fixar ao binômio arte e tecnologia (atribuído por críticos de fora deste circuito mais específico). ${ }^{5}$

Poderia reunir aqui, como endosso dessa atuação, uma série de outros projetos, como Digitofagia (2003, no MIS), envolvendo mídia tática em meios emergentes; a curadoria das exposições de arte eletrônica e digital do Sonar SP (2004); a plataforma Life Goes Mobile (2004 e 2005), quando pela primeira vez no Brasil foi discutido o celular como possibilidade artística; a exposição $O$ Lugar Dissonante (2010, Torre Malakof, Recife), em co-curadoria com Clarissa Diniz; o festival "arte.mov" (2006-2012, que comissionou projetos em várias capitais do Brasil), dedicado a pensar as novas telas portáteis e as mídias locativas; a exposição Multitude (2014, Sesc Pompeia) com sua 'curadoria de plantão', em processo contínuo; as edições do Cidade Eletronika (2012-2014, em BH), envolvendo ativismo e arte em espaços públicos; o projeto Visualismo - tecnologia e espaço público (2015, em várias localidades no RJ), com o comissionamento de 20 obras para projeções em grande escala; o ON_OFF (2012-2017, Itaú Cultural), que passou a incentivar a criação de novos projetos de performance audiovisual ao vivo, e não apenas trazer atrações internacionais; o $\operatorname{AVXLab}^{6}$ (2017, CCSP), que se desdobrou em residência artística, seminário, mostra e publicação em torno do chamado audiovisual expandido. São de fato dezenas de projetos que foram criados para se aprofundar o pensamento sobre uma cena, onde houve reflexão crítica acerca das atividades envolvidas na produção artística. Cada um deles se desdobraria em pontos-chave nas questões tratadas aqui, seja sobre o diálogo artista-curadoria, seja sobre terem vários deles viabilizado projetos que outras curadorias não viabilizariam. Vale dizer que jamais inseri um trabalho próprio em projetos de curadorias formais, talvez por acreditar nas razões que discuto no final deste texto. Creio que foram, cada qual em seu tempo, uma forma de reflexão que se colocava com alguma urgência no momento em que os projetos aconteciam. Nesse sentido, foram todos eles projetos que arriscaram falar do que ainda não estava estabelecido, funcionaram como pesquisa, como pensamento a respeito da cultura, da comunicação e da arte.

O projeto Multitude $e^{7}$ por exemplo, nasceu de um trabalho pessoal, a instalação Multidão, na exposição $L u z d a L u z$, no Sesc Pinheiros ${ }^{8}$ (2006), curada por Ana Barros, outra artista bastante etcétera. Claro, o projeto tem influência do conceito de 'multidão' de Antonio Negri e Michael Hardt, uma forma de entender as multidões em relação a mecanismos biopolíticos capitalistas. Ou seja, é um objeto de pesquisa que, ao encontrar referencias correlatas, textos, atitudes, imagens e obras de outros artistas, se transforma quase que 'naturalmente' em exposição, por explicitar o contemporâneo. Foram cruzamentos com obras de artistas como Lourival Cuquinha, Gabriela Golder, Ligia Pape, Leandro Katz e Dora Longo Bahia que impulsionaram a existência de uma exposição - da qual omiti minha própria peça, denominada Multidão, exatamente por ver que meu trabalho já acontecia na exposição de uma outra forma. O que motivou o projeto foi então um processo 
Fig 1. Website do projeto Multitude, concebido como uma plataforma para discussão ampliada do termo multidão e suas visões artísticas, filosóficas, sociológicas e políticas.

\section{MHLTIFYAE - -"}

ARTISTAS

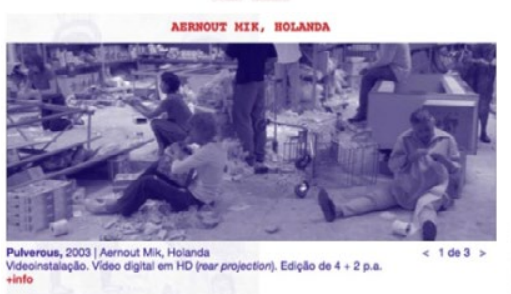

NLA YOUMrs, JORDANIA

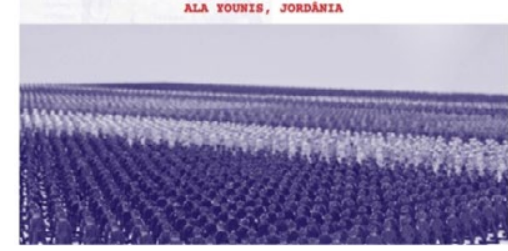

Sobre o projeto Artistas Encontros

Arquivo comu Mapeamentos Glossário imultitudepompeí

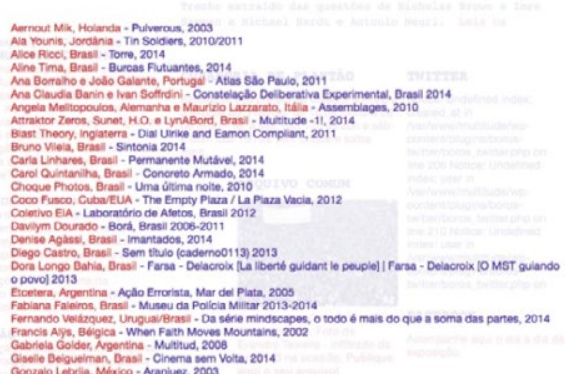

de confluência criativa em torno de um ponto comum, e não exatamente uma estratégia curatorial. Para fazer isso acontecer, foi pensado um modelo experimental de curadoria, em que uma equipe curatorial de plantão passou a receber diariamente artistas dos mais diversos circuitos que tivessem trabalhos relacionados com o conceito de multidão, e que foram sendo incorporados progressivamente ao conjunto inicial de obras. Essa curadoria funcionou no formato de um atendimento público, buscando trazer trabalhos e propostas em consonância com o tema.

É o resultado de um pensamento um tanto filosófico, um tanto sociológico e um tanto artístico que buscou reverberar as tensões percebidas na sociedade, em diálogo com as reflexões políticas na arte. Foi talvez o primeiro projeto onde os envolvidos perceberam o quanto os limites entre curadoria e ação artística estavam perdendo o sentido, seja na forma como cada inserção de novos artistas acontecia, seja na forma como as reflexões críticas e filosóficas se adentraram no espaço expositivo, em igual teor entre arte e pensamento, misturando linguagens, processos e modelos criativos. No projeto, houve a participação indistinta de artistas e pensadores como Antonio Negri, Ricardo Basbaum, Lucio Agra, Peter Pál Pelbart, Claudia Andujar, Davi Kopenawa, Suely Rolnik e Maurizio Lazaratto. Este último, por exemplo, teve tanto a exposição no seminário de suas ideias em torno de trabalho imaterial, tema sobre o qual Lazaratto é das maiores autoridades, como uma instalação artística em torno do conceito de animismo maquínico, tal como pensado por Felix Guattari, realizada em conjunto com a artista grega-alemã Angela Melitopoulos ${ }^{9}$.

Esse tipo de transversalidade, um atravessamento entre campos, meios, métodos e pontos de fala, encontra ressonância em exposições históricas. Para os que observam a relação entre o conceito de imaterialidade e 
as mídias eletrônico-digitais, é reincidente a influência marcante da exposição Les Immatériaux, curada pelo filósofo Jean-François Lyotard em 1985 no Centre Pompidou em Paris, que colocou foco na forma como as novas tecnologias da informação dão forma à condição humana. "Ao invés de escrever um livro, Lyotard fez de suas ideias filosóficas um labirinto na exposição", comenta Hans Ulrich Obrist, que assume a exposição como uma das maiores influências em sua carreira. ${ }^{10}$

Segundo o filósofo e etnógrafo Pedro Cesarino, a percepção de artistas, antropólogos e outros intelectuais convergem no âmbito criativo, pois "todos são criadores não exatamente por se imaginarem ou não como colagistas, mas por serem os responsáveis por identificar os dilemas do contemporâneo e por projetar outros mundos possíveis" (2013).

Obrist, conhecido no meio artístico pela sigla HUO, hoje a maior celebridade dentre os curadores (acreditava que poderia escrever um texto sem mencioná-lo), comenta que ${ }_{1}^{11}$ pelo fato de ser suíço e ter em sua formação a forte presença das experiências Dadaístas e do Cabaret Voltaire o faz lembrar o quanto foram experiências conduzidas exclusivamente por artistas, que produziram um impacto na forma como a arte era organizada. Os artistas introduziram formas mais anárquicas de apresentar seus trabalhos, em consonância com as condições e conceitos envolvidos, num exemplo que hoje se repete no modelo dos artist-run spaces, ou das exposições preparadas exclusivamente por artistas - um contexto particularmente transformador nos anos $1960 \mathrm{em}$ Nova Yorque, que se repetiu de forma potente nos anos 1990 em Londres e que talvez esteja se proliferando hoje em capitais menos abastadas, como São Paulo, Budapeste, Istambul, Liubliana ou Atenas

Para Celina Jeffrey, autora de uma das várias recentes publicações entituladas $O$ artista como curador, os artistas introduziram novas formas de pensar e falar sobre a cultura artística, dentre elas métodos antes associados à curadoria Esse campo de atuação, um tanto artístico, um tanto organizacional, passa a ser totalmente interligado, autofágico por vezes, permeado por propostas inclusive conceituais. É um consenso entre muitos curadores que a emergência das instalações, inicialmente em grandes exposições como a Documenta ou a Bienal de Veneza, levou a uma aproximação de procedimentos entre o 'instalar' a criação de um ambiente que potencializa a obra ou um conjunto de obras, em seus vários recursos expressivos.

Cabe perguntar: 0 artista já seria um curador, em essência, na medida em que organiza ideias, seleciona, escolhe, faz pensar, faz ver, direciona atenção ou provoca deslocamentos?

As definições dos curadores mais celebrados de todos os tempos, como Harald Szeemann e HUO, apontam para o fato de que o curador atua como mediador entre objetos e ideias, colocando diferentes esferas culturais em contato, empregando zonas de experimentação e criatividade, fazendo com que uma exposição seja um abrir de portas e funcione como uma ferramenta artística (HOFFMAN, 2017). Essas são também definições que podem ser aplicadas a muitas práticas e convicções associadas a artistas. 
Assim como o termo arte se expande (uma afirmação atribuída a Joseph Beuys), o termo curadoria também se alarga e comporta novas experiências e definições. Há riscos nessa expansão semântica - ou: "há uma ressaca de todas essas coisas na curadoria moderna", nas palavras de HUO. ${ }^{12}$ A curadoria para atividades antes improváveis de serem associadas ao termo agora se travestem de escolhas e aconselhamentos gerais: de sites, de produtos, de textos, de roupas, de etiquetas de conduta, de comida ou da carreira (coaching). Está à venda o serviço de conhecimentos ditos especializados, do saber viver, do saber escolher/decidir situações para a própria carreira do artista. Além de versões mais recentes, como a curadoria de conteúdo e de informação, que afinal começa a fazer sentido na medida em que se reconhece o espaço on-line como de fato uma extensão do espaço público, uma esfera da qual não se pode escapar facilmente.

\section{Tipologias}

Claire Bishop chama a atenção para as estratégias do curador freelance que já não é mais uma figura independente, senão uma celebridade perseguida tanto por artistas quanto por galerias, e que age como corretor de influências entre colecionadores, o mercado e de forma dependente dos patrocínios e agências que administram recursos (2007).

Durante o seminário Os Métodos e Materiais da Curadoria (Besides the Screen 2015, em Vitória), comentei possíveis tipologias de curadoria (algumas em tom jocoso) em seus caminhos mais nebulosos, como a sugestão de associação do artista à lógica das bolsas de valores, onde o mercado (ou o curador) aposta naquele/a que vai dar mais certo. É um processo que não estimula a experiência, não se viabilizam obras de maior risco, e se pensa na arte ou no artista como gerador de commodities

Considerando a competitividade da carreira curatorial "já afeita a estilos de assinaturas e artimanhas", conforme comentado por Bishop (2007), vemos se repetir também o padrão de disputas de forças, em curadorias que buscam mostrar poder por meio da exibição de obras de coleções privadas, em troca de supostos benefícios ou intercâmbio de influências, mas com pouco comprometimento com o artista em si.

Vemos curadorias bem intencionadas aplicando, por sua vez, um método típico de ilustração de ideias, em que o curador busca uma forma de se valer dos artistas para validar ou, de fato, ilustrar ideias pré-concebidas. Não que esse modelo seja realmente um problema, mas geralmente está pautado por um impulso demasiadamente egocêntrico. São atitudes instrumentais que parecem deformar e reduzir ideias a mecanismos bastante questionáveis.

E vemos e sofremos curadorias que buscam otimizar esforços por meio do mínimo diálogo (ou seja, quanto menos contato melhor), quando o artista é considerado uma peça indesejável no processo e é meramente tolerado, visando a perspectiva de uma carreira de economia de esforços. 
Haveriam outras tipologias, algumas mais ou menos provocativas. Nem tudo é carreirismo ou busca do glamour ou em torno do jet-set internacional. Em publicações mais críticas, que começam a se somar nas livrarias e em debates que contrariam o hype das feiras de arte (que explicitam sobretudo o 'quem é quem'), vemos uma ponta do que seria a idealização da prática curatorial: envolvendo diálogo, potencialização de processos, valorização das obras, projetos e pesquisa dos artistas em conjunção com a própria curadoria. Seriam perspectivas de fato interessantes a valorização efetiva das relação de respeito e aprendizado mútuo entre curador e artista, o que requer no mínimo doses mais generosas de deferência e maior compromisso.

\section{Curadoria expandida}

Os pesquisadores Daniel Jablonski e Isabella Rjeille em entrevista com o etnógrafo Pedro Cesarino comentam os processos simbióticos entre etnografia e curadoria em referência a outra 'figura de linguagem', o artista como etnógrafo, um conceito já bastante disseminado, postulado por Hal Foster em $O$ Retorno ao Real. A suposição dessa associação é a mesma buscada ao longo deste texto: a premissa de validação do 'curador-autor' e das relações produtivas que se estabelecem nesse âmbito. Com a globalização, "o curador etnógrafo desponta no fim dos anos 1980 como o responsável pelo mapeamento e pela apresentação ao público da produção artística dos confins do planeta" comentam Jablonski e Rjeille. Seria o curador etnógrafo um "mero joguete ideológico de um Ocidente em busca de novos mercados culturais ou, ao contrário, a emergência de uma real afinidade entre duas práticas com um fundo simbólico comum?" (2013, p. 5.). E ainda, a respeito da própria premissa: "O etnógrafo que deseja se confrontar à 'escritura' alheia, seja ela falada, cantada ou escrita, tem necessariamente de assumir a sua parte de criador?"

Sejam ou não essas questões típicas da visão ocidental, ou de um pós-colonialismo 'eurocentrizado', as respostas de Pedro Cesarino afirmam a necessidade de se "compreender como o pensamento ocidental (e em especial a antropologia) de fato se transformou a partir do horizonte de colaboração que então se estabelecia entre intelectuais e artistas" (2013 p. 25.).

Colaboração tem sido um motor de projetos iniciados com recursos modestos ou recurso nenhum. Nos últimos anos, percebe-se em São Paulo uma série de iniciativas que contornam a dependência de estruturas dispendiosas. No meu campo direto de atuação, cabe mencionar as oficinas em periferias e associadas a centros comunitários conduzidos pelo Labmovel ${ }^{13}$, onde sempre convidamos artistas para atuarem como educadores, em um processo curatorial em extrema proximidade com o convidado. Já participaram desse processo Raquel Kogan e Lea Van Steen, Vanessa de Michelis, Denise Agassi, Virgínia de Medeiros, Fabi Borges, Mario Ramiro e Bruno Schultze, Claudio Bueno, Fernando Velázquez, Jaime Lauriano, Fernão Ciampa e outros. 
Mais recentemente venho me dedicando aos projetos coletivos realizados na Da Haus ${ }^{14}$, uma espaço gerido por artistas, onde desenvolvemos programas nitidamente não-hierárquicos, onde a ideia de curadoria é bastante aberta e distribuída. Os projetos reincidentes e de caráter 'permanente' da casa (nunca sabemos quando exatamente poderá ocorrer o próximo) abordam meios muito diversos e comportam chamadas abertas para performances, exposições, mostras de cinema, experiências sonoras e outras possibilidades ainda em exploração. A Da Haus atua a partir da colaboração entre os integrantes e com espaços sediados na região ou com afinidade de atuação.

As performances e as exposições são os projetos mais complexos. Foram realizados duas edições do Maratona de Performances ${ }^{15} \mathrm{em}$ fevereiro de 2016 e março de 2017. Cada um dos eventos envolveu cerca de vinte performances autorais apresentadas nos espaços da casa ao longo de um dia.

o formato expositivo acontece na casa principalmente com a mostra FindeArte, onde apresentamos ao público obras que não se enquadram na lógica produtiva vigente, ou seja, trabalhos verdadeiramente em processo, executados pela primeira vez em público, ou que podem ser montados e remontados, testados e experimentados no decorrer da exposição. A primeira mostra FindeArte foi realizada em maio de 2016 e reuniu obras dos integrantes do espaço e também de artistas convidados pelo grupo: Andrei Thomaz, Camille Laurent (como residente), Dudu Tsuda, Duo B, Edouard Fraipont, Eric Mark, Fernando Velazquez, JpAccacio, Lourival Cuquinha, Matheus Leston e contou ainda com performances sonoras de Paulo Beto, Ricardo Carioba e Objeto Preto. Os curadores Ananda Carvalho e Yudi Rafael encerraram o evento com uma fala sobre espaços e iniciativas independentes na arte.

A segunda edição da mostra aconteceu em junho de 2017 e contou com os seguintes artistas: Aaron Fernandes, Alini Santini, Andrei Thomaz, Bella, Bruno Palazzo, Dora Longo Bahia, Eduardo Duwe, JpAccacio, Lucas Bambozzi, Marcelo do Campo, Mario Ramiro, Mauricio Ianês, Mirella Brandi, Muep Etmo, Philip Somervell, Rochelle Costi, Rodrigo Gontijo, Sergio Basbaum, Simon Fernandes, Stefanie Egedy, Thomas Rohrer, Tomaz Klotzel e Vinicius Maffei. Uma performance do grupo Cão (Dora Longo Bahia, M. Ianês, R. Carioba e B. Palazzo), uma banda cuja sonoridade a princípio não cabe num espaço residencial, demarcou o caráter multimidiático e de confluência de linguagens e gerações associado à casa.

O improviso é um dos aspectos que mais caracteriza os projetos da Da Haus (em tempo, um nome herdado de uma cacofonia associada ao dadaísmo), um espaço que valoriza o ideal de se fazer pelo devaneio criativo, de aceitar o risco como oportunidade mesmo de teste e experiência. Novamente, valores que se misturam entre as obras e as exposições mais celebradas pela crítica. Parece que um século depois das movimentações que se ensejaram num ambiente modernista nos anos 1920, temos desafios similares de ruptura. Trocadas algumas bandeiras, há sempre uma militância em pauta para aqueles que não se veem representados pelos mecanismos e sistemas vigentes. É para esse contexto que percebemos, em projetos como os da Da Haus, que os esforços são sempre válidos e recompensadores, mesmo que 'sísificos', mesmo que o terreno continue árido. 

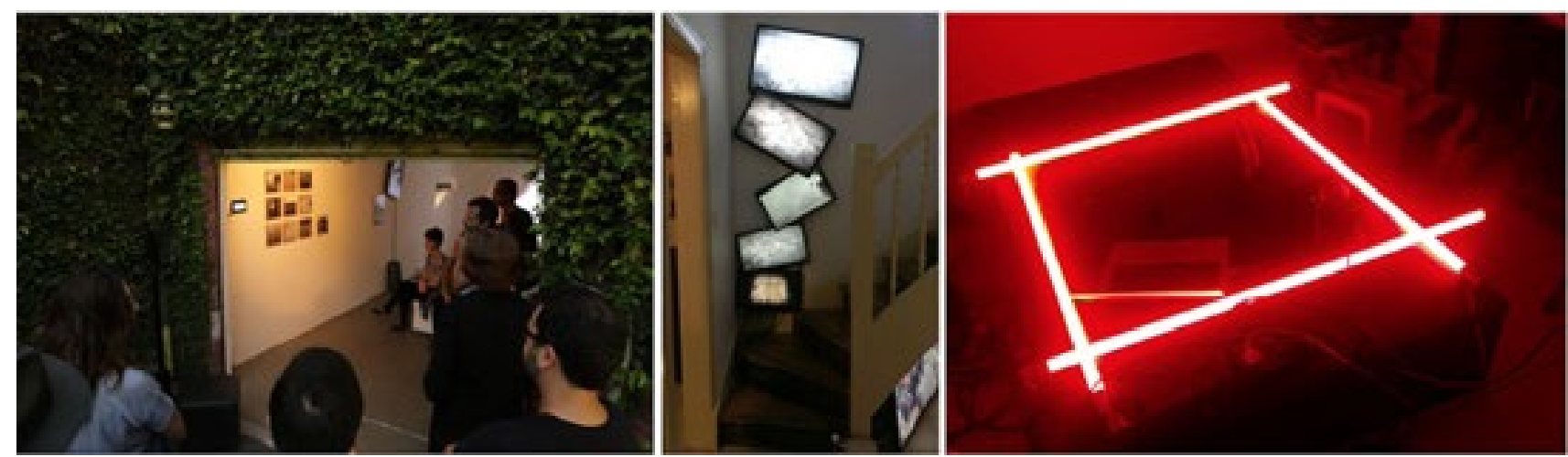

Fig 2. Cenas de exposições na Da Haus em 2016 e 2017, com trabalhos de JP Accacio, Lucas Bambozzi e Camille Laurent.

\section{Instigados pela urgência}

É de causar certa intriga ou mesmo certa ponta de inveja entre artistas o quanto os projetos mais conhecidos de HUO se valem de ideias em torno de processos e colaboração. Entre seus projetos mais autorais (e entre os que mais afirma gostar), está Do it, em que ele pede aos artistas, numa espécie de ação colaborativa ou de crowdsourcing, para contribuírem com instruções a serem compiladas e possivelmente realizadas por quem se aventurar. Iniciado em 1993, o projeto é constantemente re-editado e segue on-line, por meio do site e-Flux, instigando participações que atualizam o projeto a cada dia. Considerando-se o projeto como um ambiente de exercício de liberdade de criação e colaboração, pode-se pensar que a iniciativa bem poderia ter sido conduzida por um net-artista, por um coletivo ativista ou pela militância midiática de um artista como Ai Wei Wei.

Instigar os participantes é um recurso mencionado por Jens Hoffmann como uma das articulações curatoriais mais bem-sucedidas, que menciona as exposições de Szeemann e HUO como icônicas nesse sentido (2017 p. 27, p. 75.).

No caso da Da Haus, isso se dá não como estratégia de persuasão, mas espontaneamente, dentro de proporções 'domésticas', em torno de uma construção comum, de uma necessidade de se fazer, quase urgente, quase incondicional.

Em várias das exposições que fiz ou nas que vejo vários artistas se esforçando em fazer, creio que se trata de direcionar essas iniciativas para algo que apenas os projetos sem grandes patrocínios parecem poder almejar: de que aquela exposição vai criar a criação de uma comunidade e de , de que vai gerar um real senso de pertencimento. Uma condição menos dependente de um mercado dominado por celebridades curatoriais, e que parte da perspectiva de que talvez ainda se possa comportar risco criativo, alguma autonomia, e uma certa independência. São iniciativas que acreditam poder se desvencilhar do esnobismo vigente nos circuitos estabelecidos, do 'puxa-saquismo' dos grandes nomes, do trâmite de influências, do arremedo dos padrões do hemisfério norte, da repetição dos nomes reincidentes 
no mercado de valores - em um jogo de ascensão e histeria, de cartas muito marcadas. E, muito importante, de que possa haver um compartilhamento dos frutos obtidos, entre os envolvidos e outros artistas, de forma generosa. Para tanto, há que se observar as ciladas e os truques reincidentes. Há que se perceber os mecanismos viciados e os padrões arquetípicos.

Volto a questões iniciais: se um artista pode ser um curador, que escolhas essa condição ambígua determina? A serviço de que decisões e situações, para além da própria carreira, pode operar essa prática?

Fig 3. O gráfico mostra um rascunho para o entendimento sobre as possibilidades de cruzamento entre campos de interesse do artista e do curador (colaboração de Fernando Velazquez)

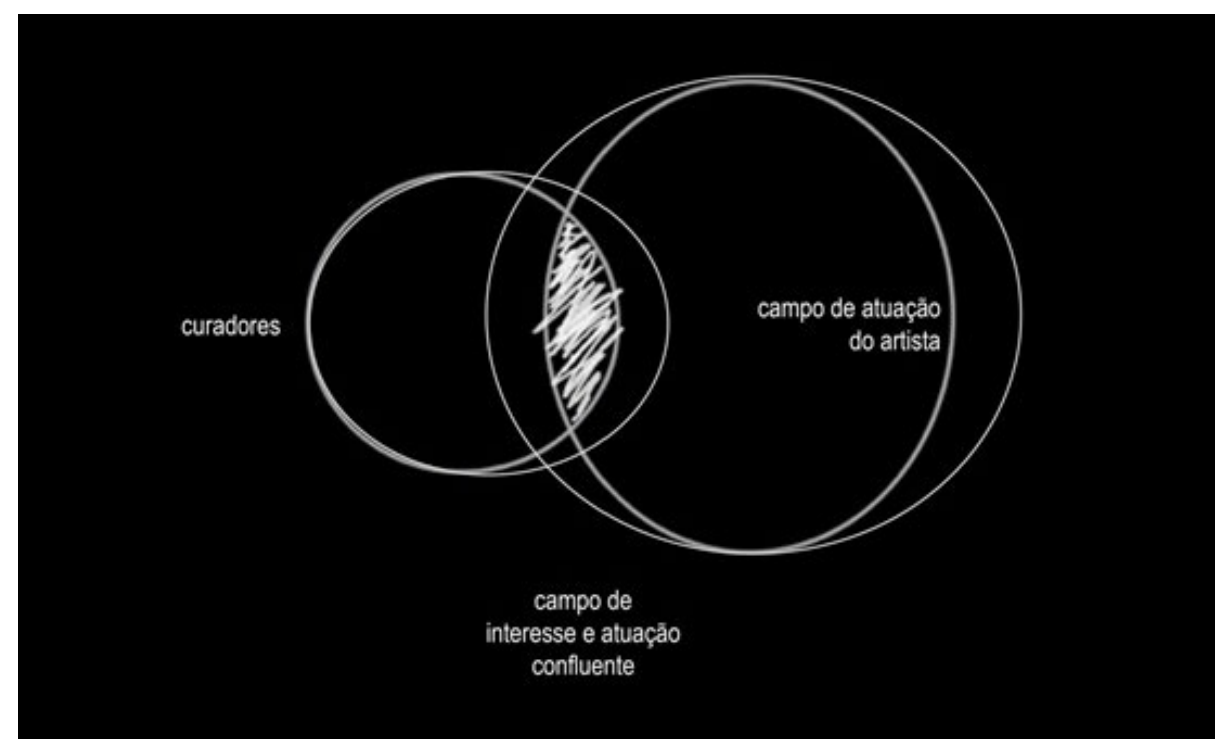

Hoje, observando os projetos curatoriais nos quais me envolvi, e que me fizeram ser o artista que cabe em mim, o pesquisador que a inquietação me levou a ser, ou o 'devir-curador' que me acomete de vez em quando, percebo o quanto essa experiência me faz compreender com maior amplidão os processos e circuitos da arte.

Essa compreensão torna um tanto mais conscientes os processos e cuidados que passam a fazer diferença crucial na (in)distinção entre curador e artista. São detalhes, como um certo 'maravilhamento' que se pode ter ao cuidar da exposição de um/a artista como se o/a artista fosse você mesmo/a. Ao desejar para os/as artistas as mesmas oportunidades que você desejaria para si próprio/a. Ao entender sutilezas que os pares reconhecem, mas que talvez não seja do interesse dos curadores operar.

$\mathrm{Na}$ busca por uma simbiose produtiva entre obras e curadorias, talvez seja necessário pensar em alguns parâmetros que podem se iniciar a partir da aplicação de filtros específicos para se tratar de determinados temas ou meios. Pensar certos temas, analisar a condição e situação apresentada, não tomar o genérico como regra, podem ser condutas que fazem uma curadoria se diferenciar qualitativamente de outra. Como nos ensinam os etnógrafos e antropólogos (aprendamos com eles), o conhecimento 
do ambiente, o reconhecimento da diferença, a abertura a conceitos que não se encaixam em formações pré-estabelecidas são pontos essenciais nos processos de aprendizado e tradução de linguagens e experiências. Sim, tradução de experiências: de uma experiência física em um relato, de um percurso em uma imagem, de um texto em uma deleite estético - aceitar que nossa experiência de mundo pode depender muito de traduções pode conferir maior potência ao ato artístico.

Que se conheça também o meio técnico envolvido pela obra e pelo pensamento lógico do artista - ou, num extremo, que o conceito da obra possa estar baseado na compreensão do algoritmo. Sim, por que não? Há uma fobia desmedida em relação ao campo das mídias eletrônicas e digitais. Se por um lado os artistas do código e da programação desfilam conhecimentos demasiadamente específicos, por outro se disparam fobias e o total desconhecimento dos procedimentos ou das capacidades de certas técnicas e meios (códigos inclusive) produzirem linguagem. Falo de linguagens de interesse amplo e expandido, e não apenas relegadas ao seu aspecto técnico mais aparente.

Que se pense na exposição como exercício estético, como forma de proporcionar uma experiência de valor sensorial, único ou minimamente memorável. Para os que associam tecnologia a alienação, cabe lembrar que o campo da crítica dos meios informacionais é o que mais tem produzido reflexões com viéses políticos, sociais, econômicos e humanos, atestados ao longo de décadas em listas de discussão ${ }^{16}$ onde se discutem esses temas de forma cruzada e transversal, envolvendo também curadoria e arte contemporânea. Que seja sobretudo um exercício ético, um modelo de acontecimento (político talvez), comprometido eticamente. Onde não sejam desgastadas as pontas mais frágeis, o que significa quase sempre um custo maior para o lado do artista. E, finalmente, para que não seja necessário acobertar trâmites escusos ou relações de poder obscuras, que eventualmente vão implicar artistas, público e crítica.

Se o início da digitalização dos processos de comunicação capturou alguns de nós com a valorização de processos multitask e de atenção difusa, ou nos fizeram acreditar que a hiperconectividade seria um valor a ser colocado acima da atenção, dedicação e envolvimento, talvez tenhamos nos equivocado. Processos curatoriais, especialmente aqueles pensados por artistas, mesmo que anárquicos, requerem envolvimento e atenção, em medidas e momentos diferentes talvez, como toda criação.

São perspectivas para se reivindicar uma dimensão ética e transversal de curadoria...

Se o curador pensa no seu trabalho apenas como profissional, um job (palavra irritante, não?) a ser finalizado o mais rápido possível, talvez esteja aqui um fator de distanciamento definitivo do potencial criativo e de sensibilização artística, que é a possibilidade do processo resultar na viabilização de experiências verdadeiras para os envolvidos. Trata-se muito mais de operar pelo outro e/ou com o outro (sim, o outro é um artista), em sintonia de interesses. 
Fig 4. Apocalipopótese, 1968, no Aterro do Flamengo, fora do museu: um misto de instalação, exposição e manifesto, talvez o projeto mais ambicioso do programa político de Hélio Oiticica. "A manifestação mais importante de seu desejo de intervir na esfera pública, aspirando criar uma comunidade que respondesse e ampliasse o horizonte de emancipação que seu trabalho implicava" (2015).

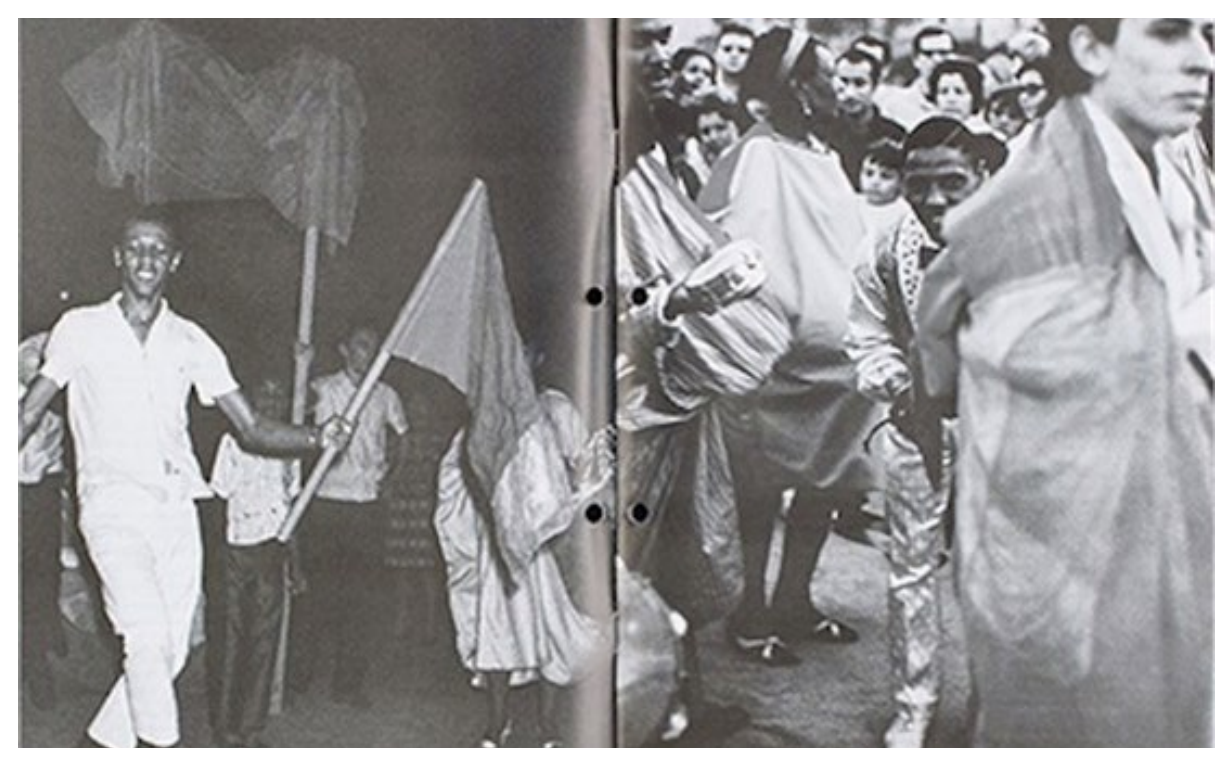

\section{Como alguns de nós:}

Cabe acreditar que o artista-curador pode ser esse sujeito a fazer vazar o campo de interesse artístico (amplo, geral, contínuo) para uma área que não é apenas do interesse do curador. Foi a partir dessas divagações que, em algum momento, pensei, com total honestidade, e a princípio em silêncio, comigo mesmo, para não denotar o equívoco de alguma pretensão: sim, talvez algumas dessas curadorias sejam obras. Não são aquelas que Jeremy Deller faz com a consciência de estratégia ou precisão do lugar que ocupa no sistema vigente. Não são as casas magníficas que Rirkrit Tiravanija cria para viabilizar convívios, mas são a expressão sincera do que em mim se coloca como criador. Quando menciono a palavra honestidade, é porque passei a ver essa possibilidade de potencializar uma cena, de espalhar contaminações assertivas, de perceber a urgência do fazer, como uma condição verdadeiramente artística, não como retórica, mas a partir de uma admiração intensa por essas práticas.

O 'arrebatamento' pela criação pode surgir de uma confluência desses pontos acima. $\mathrm{E}$ de que o entendimento de arte em confluência com a vida não é muito fabricável, não pode nunca ser um mero discurso. Tem que ser vivido, em estado continuado, às vezes sem descanso.

A frase 'Não sabendo que era impossível, foi lá e fez' (They did not know it was impossible, so they did it!) parece se encaixar em algum ponto dessas reflexões sobre o caráter acidental ou inadvertido das intenções que movem um indivíduo. Curiosamente, sua versão original é atribuída tanto a Jean Cocteau como a Mark Twain (o que é emblemático sobre as verdades que se estabelecem de forma paralela à pesquisa curatorial). Creio que fui curador sem saber que era, acidentalmente. Da mesma forma como muitos o foram. 
Pois se não somos exatamente curadores, somos facilitadores, viabilizamos participações, disparamos novos trabalhos, criamos espaços auto-geridos, pensamos em exposições autônomas, acreditamos em organizações que se mantêm firmes apesar das inconveniências, insistimos em instigar, em sermos instigados, nas urgências e nas formas expandidas de se pensar a arte e a curadoria. Portanto, isso não é um manifesto contra curadores. Pode ser mesmo que muitos de nós sejamos como eles, e eles como a gente. dação Telefonica, da Espanha - encontra-se na 16ª edição.

2 http://www.theartistascurator.org/ Acesso em 04 Ago. 2017

$3 \mathrm{Na}$ ordem citada, caberia comentar alguns dos principais projetos curatorias desses artistas: Aguilar: o período em que esteve como diretor da Casa das Rosas, entre 1995 e 2000; Basbaum: o objeto NBP, Novas Bases para a Personalidade, que propõe a obra como uma rede de relações; Graziela Kunsch, cujos trabalhos como os apresentados na $29^{a}$ e $31^{a}$ Bienal de São Paulo são processos em que se posiciona como curadora, crítica, educadora e editora (além de seus projetos com performances e vídeos); Giselle, que realizou inúmeras curadorias, como os projetos HTTP (som, vídeo, tag, pix), mostra de artistas brasileiros no ISEA Ruhr 2010, III Mostra 3M de Arte Digital: Tecnofagias, Virada Cultural 2013, etc, sempre em situações exemplares, do ponto de vista deste texto, de extensão de oportunidades; Velazquez: exposições Adrenalina e Periscópio; Marcus Bastos: fez a curadoria de Geografias Celulares, apresentada pela Fundación Telefônica em Buenos Aires e Lima (2014); Roberto Traplev: projeto Recibo e ações de Traplev Orçamentos, por meio do qual organiza curadorias, exposições e projetos colaborativos desde 2005; Jorge Menna Barreto, que apesar de não se encaixar propriamente nos modelos pensados aqui, pode ser citado por seus projetos como Desleituras e Café Educativo, um misto de projetos colaborativos, práticas educativas e ações artísticas; Kika: dentre outros, com Exquisite Corpse Video Project, atualmente no quarto volume, envolvendo videoartistas de todo o mundo; Mendonça, com vários projetos envolvendo rede e performance; Sonia, com as mostras Ecosistemas, em 2013 e 2014, na Praça Victor Civita; Claudio Bueno: ações curatoriais e ou educativas através das "plataformas" Explode! e Intervalo-Escola; Menotti, com seus projetos tape deck solos na 29a Bienal de São Paulo, e Estudos da Recepção em Vitória, cinema de WhatsApp e o projeto Besides the Screen, que viabiliza esta própria publicação; Fred Paulino, com as exposições Gambiólogos e as edições da Facta; Daniel, sempre envolvendo coletividades em seus projetos, sendo o mais recente a exposição "Agora somos todxs negrxs?" junto ao Videobrasil. Desenvolver e discutir cada um desses projetos demandaria um espaço indisponível no presente texto e publicação.

4 A Diphusa foi originalmente uma associação formal de distribuição de videoarte, criada com o intuito de representar artistas, organizar mostras e difundir obras de vídeo independente no Brasil e no exterior nos moldes de distribuidoras de vídeo como a Electronic Arts Intermix, Video Data Bank e Heure Exquise, uma vez que a existência de galerias com interesse em vídeo era praticamente nula naquele contexto. Faziam parte da Diphusa, além de mim, os artistas e/ou produtores Lucia Koch, Jurandir Muller, João Claudio de Sena, Rubens Mano, Christine Mello e Kiko Goifman.

5 Um relato mais detalhado sobre esse período na Casa das Rosas, incluindo informações sobre as exposições, muitas delas curadas por artistas, encontra-se publicado no texto "Esquecimento e conveniência", de minha autoria, publicado em Futuros Possíveis: arte, museus e arquivos digitais, organizado por Giselle Beiguelman e Ana Gonçalves Magalhães, Edusp, 2014. 
6 Projeto com co-curadoria de Demetrio Portugal, e com concepção e desenvolvimento envolvendo também Tatiane Gonzalez, Eduzal Fernandes e Carol Caffé.

7 Para dar conta de multiplicidade de pontos observação, a partir de campos distintos, o projeto Multitude foi desenvolvido por Andrea Caruso e Lucas Bambozzi a partir da criação de um conselho formado por Peter Pál Pelbart, Natacha Rena, Lucio Agra e Rodrigo Araújo. A curadoria de plantão, pensada para o projeto desde sua origem, foi conduzida por Andrés Hernándes, Christine Mello, Lucio Agra, Paula Borghi e Ricardo Muniz Fernandes.

8 Versões distintas foram criadas para o Laboratório Arte Alameda na Cidade do México (2011), Favela Maré no Rio de Janeiro (2013) e Virada Cultural em São Paulo (2013), sempre considerando a pertinência das ações representadas com relação ao contexto local.

9 Trata-se da videoinstalação "Assemblage", composta por 3 telas em formato verticalizado (duas com imagens e uma com texto), que exibem conversas e pensamentos do próprio Guattari, bem como de Suely Rolnik, Peter Pál Pelbart e do antropólogo Eduardo Viveiros Castro, dentre outros. 10 The art of curation, entrevista com Hans Ulrich Obrist. The Guardian, Sunday 23 March 2014 https://www.theguardian.com/artanddesign/2014/mar/23/hans-ulrich-obrist-art-curator. Acesso: 20 Jun 2017.

11 Declaração feita durante a Miami Basel (2014) no debate The Artist as Curator, exatamente com artistas curadores. https://www.youtube. com/watch?v=68pVopOV-FM\&t=3654s. Acesso em 07 Ago. 2017.

12 The art of curation, entrevista com Hans Ulrich Obrist. The Guardian, Sunday 23 March 2014 https://www.theguardian.com/artanddesign/2014/mar/23/hans-ulrich-obrist-art-curator Acesso: 20 Jun 2017

13 Projeto criado com Gisela Domschke em 2012. Atuou até meados de 2016 em uma série de iniciativas, que renderam dentre outros méritos a menção honrosa no prêmio Ars Electronica de 2013 pela criação de comunidades digitais.

14 A Da Haus tem como responsáveis Eduardo Duwe, Mirella Brandi, Muep Etmo (Fabio Torres), Rodrigo Gontijo e eu. Participam também do coletivo e da condução das atividades os artistas Camille Laurent, Aaron Fernandes, Cassandra Mello, Stefanie Egedy e Simon Fernandes. 15 A edição da Maratona de Performance em 2016 reuniu os artistas: Alexandre De Angeli, Bruno Mendonça, Camille Laurent, Clássicos de Calçada, Dani Spadotto, Denise Agassi, Felipe Julian + Sandra-x, Herbert Baioco, Joanna Junqueira, Jonathan Gall, Leticia Rita, Marcia Beatriz Granero, Marcio Vasconcelos, Melina Furkin, Olivier Kaminski e Rafael Amambahy. Em 2017: Camille Laurent + Stefanie Egedy, Coletivo Espectro, Felinto, Kefer, Karina Montenegro + Dudu Tsuda, Manuel Lima, Fabia Karklin, Carolina Sudati, Carlos Monroy, Coletivo Alternância, Lorena Pazzanese, Mariana Rocha, Pablo Villavicencio + Fabricio Masutti, Simon Fernandes, Ana Lucia Magalhaes, Claudia Muller, Sara não tem nome, Thelma Bonavita, Tizo All, Tuca Paoli, Vic Von Poser, Chineladaaa, Edu Zal + Julieta Benoit, Marcus Bastos + Alexandre Peterhaensel.

16 Algumas dessas "ágoras" de discussão e crítica online: Nettime <http://www.nettime.org>; Empyre <http://empyre.library.cornell.edu>; Netbaviour <http://www.netbehaviour.org/mailman/listinfo/netbehaviour>; CRUMB <http://www.crumbweb.org/>. Todas as aqui listadas estão ativas há mais de 15 anos. 


\section{Bibliografia}

AMOR, Monica. BASUALDO, Carlos. Hélio Oiticica, Apocalipopótese, 1968. In The Artist as Curator \#8, Mousse, No 49, 2015. http://moussemagazine.it/taac8-a/ Acesso: 29 Jun. 2017 BISHOP, Claire. What Is a Curator? The rise (and fall?) of the auteur curator, IDEA, issue 26, 2007. http://idea.ro/revista/?q=en/node/41\&articol=468 Acesso em 01 Jul. 2017 CESARINO, Pedro; JABLONSKI, Daniel; RJEILLE. Isabella. O curador como etnógrafo, o etnógrafo como curador. In Máquina de escrever, Rio de Janeiro, Capacete, 2013.

FOSTER, Hal. The return of the real: the avant-garde at the end of the century. London: The MIT Press, 1996.

HOFFMANN, Jens. (Curating) From A to Z. Zurique. JRP Ringler. 2017.

FILIPOVIC, Elena. When Exhibitions Become Form: On the History of the Artist as Curator. In: The Artist as Curator \#0" Mousse, No. 41, 2015 http://moussemagazine.it/taac0/ Acesso 05 Ago. 2017

\section{Websites}

The Artist as Curator - http://www.theartistascurator.org/ Acesso: 01 Ago. 2017 AVXLab <http://avxlab.org/> Acesso: 01 Ago. 2017 Do it (plataforma) http://projects.e-flux.com/do_it/manuals/0_manual.html Acesso: 30 Jul. 2017 Multitude <www.projetomultitude.net>01 Ago. 2017

\section{Créditos das imagens}

As fotos são do autor do texto, com exceção de Apocalipopótese, reproduzida a partir do livro The Artist as Curator <http://www.theartistascurator.org/> 